\title{
Kernel Color of Three Black Walnut Cultivars after Delayed Hulling at Five Successive Harvest Dates
}

\author{
Michele Renee Warmund ${ }^{1,2}$ \\ Department of Horticulture, 1-31 Agriculture Building, University of \\ Missouri, Columbia, MO 65211
}

Additional index words. Juglans nigra, L*, chroma, hue angle, spectrophotometer

\begin{abstract}
Emma K', 'Kwik Krop', and 'Sparrow' black walnuts (Juglans nigra L.) were collected weekly in Sept. and Oct. 2007 to determine the effect of delayed hulling of fruits on kernel color at successive harvest dates. Delayed hulling of fruits resulted in lower kernel color values, including $\mathbf{L}^{*}$, chroma, hue angle, and $\mathbf{L C H}$ sum $\left(\mathbf{L}^{*}+\right.$ chroma + hue angle values) than those of fruits that were immediately hulled after harvest. 'Sparrow' kernels were visually the darkest brown color after delayed hulling. However, the effect of delayed hulling (i.e., change in kernel LCH sum values) over all harvest dates was greatest for 'Emma K'. LCH sums of kernels generally decreased as the time of harvest was delayed. For 'Sparrow', mean kernel LCH sums from immediately hulled fruits decreased sharply from the third week of harvest on 20 Sept. (i.e., the "normal" date of harvest) to the next week. This decrease in $\mathrm{LCH}$ sums represented a change in kernel color classification from medium brown at Week 3 to dark brown in Week 4. Visual color changes for 'Kwik Krop' were less apparent as a result of the narrow range of color over harvest dates.
\end{abstract}

Eastern black walnuts (Juglans nigra) are prized for their unique kernel flavor when consumed fresh or in confectionary products. Approximately $90 \%$ of the crop is currently produced from native seedling trees and hulling of nuts is often delayed for several weeks (B.K. Hammons, personal communication). However, growers receive as much as $\$ 1.39$ more per kilogram for hulled fruits harvested from improved cultivars produced on grafted trees than for fruits from seedling trees. These cultivars produce fruits with thinner shells, greater percent kernel, and larger kernel size than those from native trees (Reid et al., 2004). Also, most cultivars yield larger kernel pieces when cracked than those from wild trees.

In addition to shell thickness, kernel size, kernel percent, tendency to yield large pieces of kernels when cracked, and flavor, kernel color is a component of black walnut fruit quality (Funk, 1979). However, kernel color

Received for publication 11 July 2008. Accepted for publication 21 Aug. 2008.

Contribution from the Missouri Agricultural Experiment Station project 322. This work was partially supported by the University of Missouri Center for Agroforestry under cooperative agreements 58-6227-1-004, 58-6227-2-008 and 58-6227-5-029 with the USDA-ARS Dale Bumpers Small Farms Research Center, Booneville, AR.

Any opinions, findings, conclusions, or recommendations expressed in this publication are those of the author and do not necessarily reflect the view of the U.S. Department of Agriculture.

${ }^{1}$ Professor

${ }^{2}$ To whom reprint requests should be addressed; e-mailwarmundm@missouri.edu can be highly variable and is apparently affected by cultural practices. Fruits that fall to the ground naturally near the end of the growing season have low-quality, darkcolored kernels (Duke, 2001; Taylor and Perry, 1986). In contrast, fruits harvested earlier in the season with tree shakers generally have high-quality, light-colored kernels (Brawner and Warmund, 2008). It has been observed that delayed hulling is associated with darker colored kernels, but the effect has not been quantified (Chase, 1941; Reid et al., 2004; Stoke, 1941). Because light-colored black walnut kernels are more desirable than dark-colored kernels (Stoke, 1941), this study was conducted to quantify the effect of delayed husk removal on kernel color when fruits of three cultivars were harvested at 5 successive weeks.

\section{Materials and Methods}

Five trees each of 'Emma K', 'Kwik Krop', and 'Sparrow' growing in a commercial orchard near Windsor, MO, were selected based on similarity in tree age ( 28 to 30 years old), crop load, and location within the site. Trees were grafted onto seedling $J$. nigra rootstock and were spaced $6.1 \times 6.1 \mathrm{~m}$ apart. Fertilizer $(13 \mathrm{~N}-5.7 \mathrm{P}-$ $10.8 \mathrm{~K}$ ) was applied annually in February at $22.7 \mathrm{~kg} \cdot \mathrm{ha}^{-1}$. Trees received only natural rainfall. However, from 1 May to 11 Oct. 2007 (last harvest date), the total precipitation was $46.3 \mathrm{~cm}$.

In 2007, 30 walnuts per tree were sampled randomly at weekly intervals for 5 consecutive weeks from each cultivar. Based on historical data collected in Missouri (Mark Coggeshall, unpublished data), sampling dates were selected for each cultivar with the third date as the "normal" time of harvest. 'Sparrow' and 'Emma K' trees were harvested weekly from 6 Sept. to 4 Oct. Harvest dates for 'Kwik Krop' trees were 13 Sept. to 11 Oct. Walnuts were removed from the tree with a 3.8-m-long fruit picker (Ez Connect; Village Blacksmith, Industry, CA).

Immediately after harvest, 15 walnuts from each tree were hulled with a locally produced hulling machine (Lane, 2000) and remnants of the hull were removed from the nut surface using an electric bench grinder with a $15.2-\mathrm{cm}$-diameter wire brush. Walnuts were then stored at $23{ }^{\circ} \mathrm{C}$ at $50 \%$ relative humidity without air movement for 5 weeks to dry. For the delayed hulling treatment, the remaining 15 nuts per tree from each cultivar were stored at $23{ }^{\circ} \mathrm{C}$ at $50 \%$ relative humidity for 2 weeks before hulling. After 2 weeks, these fruits were hulled and stored for 5 weeks as previously described.

After drying, all walnuts were cracked with a mechanized cracker (Lane, 2000). The largest piece of each nut was selected for color measurement. Kernel color (L*, chroma, and hue angle) was recorded using a handheld spectrophotometer (CM-2600d; Konica Minolta Corp., Ramsey, NJ) with a 6$\mathrm{mm}$-diameter aperture and specular light was included. Two readings of kernel color values ( $\mathrm{L}^{*}$, chroma, and hue angle) at two locations were averaged. The $\mathrm{L}^{*}$ value ranges from 0 (black) to 100 (white). Chroma (C) is the departure from white toward pure hue color and represents brightness (McGuire, 1992). Hue $(\mathrm{H})$ angle quantifies color, in which $0^{\circ}=$ purplish red, $90^{\circ}=$ yellow, $180^{\circ}=$ bluish green, and $270^{\circ}=$ blue (Voss, 1992). The sum of $\mathrm{L}^{*}$, chroma, and hue angle (LCH sum) was also calculated for each kernel for comparison of kernel color at successive harvest dates (Fig. 1). For eastern black walnut, LCH sums 150 or greater are classified as light-colored, sums of 149 to 126 are medium-colored, and values 125 or less are dark-colored (Brawner and Warmund, 2008).

Color values from each cultivar were analyzed separately. Values were subjected to an analysis of variance using a randomized complete block design (each tree was a block) and a factorial arrangement of two hulling treatments and five harvest dates. Fruits were randomly sampled from a tree at weekly intervals and randomly assigned to an immediate or delayed hulling treatment. Data were analyzed using the SAS general linear model procedure (Version 9.1; SAS Institute, Cary, NC) and means were separated by Fisher's least significant difference test $(P \leq 0.05)$. Polynomial contrasts were used to test responses over time when treatment $\times$ date interactions were significant.

\section{Results and Discussion}

$\mathrm{L}^{*}, \mathrm{C}, \mathrm{H}$, and $\mathrm{LCH}$ sum values of 'Emma $\mathrm{K}^{\prime}$ kernels hulled immediately after harvest 
were higher than those of kernels that were hulled 2 weeks later (Table 1; Fig. 2). Kernel color values of 'Emma K' nuts from both treatments generally decreased at successive harvest dates. Thus, kernels were visually darker ( $\mathrm{L}^{*}$ value) brown $(\mathrm{H})$ and duller $(\mathrm{C})$ in color at later harvest dates than those collected earlier.

The effect of delayed hulling and date of harvest for 'Kwik Krop' kernels was similar to that for 'Emma $\mathrm{K}$ ' kernels for all color variables, with the exception of $\mathrm{L}^{*}$ (Table 1; Fig. 2B). $\mathrm{L}^{*}$ values for kernels of 'Kwik Krop' fruits that were immediately hulled were similar for the first three harvest dates. At the fourth harvest date, the $L^{*}$ value decreased slightly when compared with kernels harvested at the first and second harvest dates. By the last harvest date, kernels were darker in color than those harvested at all previous dates. In contrast, $L^{*}$ values for kernels of 'Kwik Krop' fruits that had delayed hulling decreased from the first to the second harvest date, but were similar during the next 2 weeks. By the last harvest date (Week 5), kernels from fruits with delayed hulling were darker in color than those harvested at Weeks 1 and 2 (Fig. 2B). Thus, L* exhibited a quadratic response $(P \leq 0.01)$ to the interaction of treatment and harvest date.

During the first three harvest dates, $\mathrm{L}^{*}$ and $\mathrm{H}$ values of 'Sparrow' kernels that were immediately hulled after harvest generally decreased slightly (Fig. 2C). However, decrease in $\mathrm{L}^{*}$ values. In contrast, $\mathrm{C}$ values
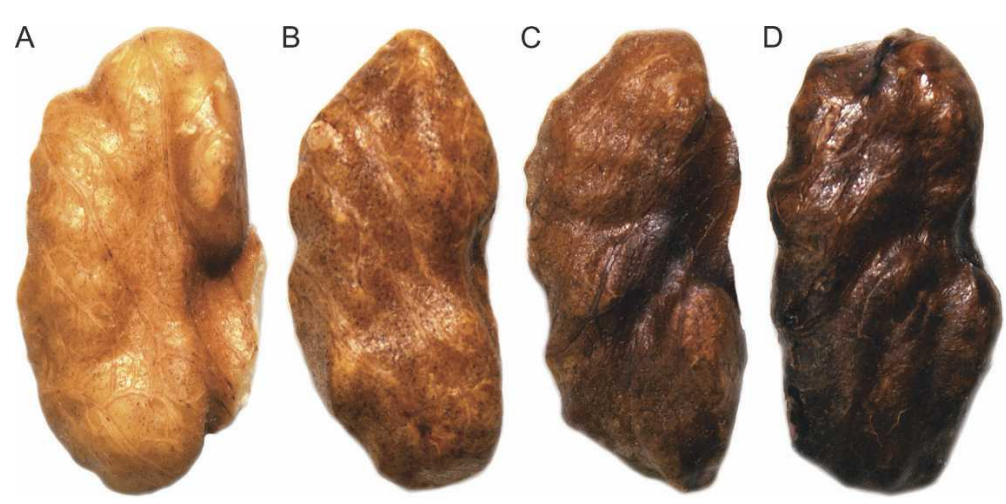

Fig. 1. Color values for 'Emma K' kernels: $(\mathbf{A}) \mathrm{L}^{*}=52.18$, chroma $=27.55$, hue angle $=72.12$, and $\mathrm{LCH}$ sum $=151.85 ;(\mathbf{B}) \mathrm{L}^{*}=41.12$, chroma $=25.48$, hue angle $=66.29$, and $\mathrm{LCH}$ sum $=132.89 ;(\mathbf{C}) \mathrm{L}^{*}=$ 34.98 , chroma $=18.91$, hue angle $=56.58$, and $\mathrm{LCH}$ sum $=110.47$; and $(\mathbf{D}) \mathrm{L}^{*}=30.30$, chroma $=11.87$ hue angle $=50.00$, and LCH sum $=92.17$.

of kernels decreased steadily during the harvest period. When hulling of fruits was delayed by 2 weeks, the $\mathrm{L}^{*}, \mathrm{C}$, and $\mathrm{H}$ values decreased gradually from Week 1 to Week 5 (Fig. 2C). Thus, $\mathrm{L}^{*}, \mathrm{C}$, and $\mathrm{H}$ values exhibited a quadratic response $(P \leq 0.01)$ to the interaction of treatment and harvest date. LCH sum of 'Sparrow' kernels was lower (i.e., darker brown color) when hulling and the harvest date was delayed (Table 1; Fig. 2C)

Because of the different harvest seasons for the cultivars, this study did not directly compare data from the three cultivars. However, the results showed that kernel color of all three cultivars can be altered by delaying husk removal and the date of harvest, but the impact of these two factors appeared to vary by cultivar. For example, delayed hulling adversely affected 'Emma $\mathrm{K}$ ' the most in that the mean kernel $\mathrm{LCH}$ sum from fruits hulled immediately was 140 , whereas that of kernels from fruits in the delayed hulling treatment averaged 125 .

The effect of date of harvest on kernel color was greatest for 'Sparrow'. In this study, changes in kernel color for 'Emma $\mathrm{K}$ ' and 'Kwik Krop' were detected with the spectrophotometer, but visual changes in color over the five harvest dates were relatively slight, especially for 'Kwik Krop'. In an earlier study (Brawner and Warmund, 2008), 'Kwik Krop' kernels were the most difficult to sort visually because of their narrower range of color values than those of 'Emma K' and 'Sparrow' when harvested over a similar 5-week period. In contrast to 'Kwik Krop' and 'Emma K', the average from Weeks 3 and 4, there was a large

Table 1. Probability of significant differences for the effect of a 2-week delay in husk removal and the date of harvest on the color ( $\mathrm{L}^{*}$, chroma, hue angle, and LCH sum) of 'Emma K', 'Kwik Krop', and 'Sparrow' black walnut kernels harvested in 2007.

\begin{tabular}{|c|c|c|c|c|c|c|c|c|c|c|c|c|c|}
\hline & \multirow[b]{2}{*}{$\mathrm{df}^{\mathrm{y}}$} & \multicolumn{4}{|c|}{ Emma K } & \multicolumn{4}{|c|}{ Kwik Krop } & \multicolumn{4}{|c|}{ Sparrow } \\
\hline & & $\mathrm{L}^{*}$ & $\mathrm{C}$ & $\mathrm{H}$ & LCH sum & $\mathrm{L}^{*}$ & $\mathrm{C}$ & $\mathrm{H}$ & LCH sum & $\mathrm{L}^{*}$ & $\mathrm{C}$ & $\mathrm{H}$ & LCH sum \\
\hline Date (D) & 4 & ** & $* * *$ & $* * *$ & $* * *$ & *** & *** & $* * * *$ & $* * *$ & *** & $* *$ & $* * *$ & $* * *$ \\
\hline
\end{tabular}

${ }^{2}$ Harvest dates 1, 2, 3, 4, and 5 were 6, 13, 20, and 27 Sept. and 4 Oct., respectively, for 'Emma K' and 'Sparrow', whereas harvest dates 1, 2, 3, 4, and 5 were 13, 20, 27 and Sept. and 4 and 11 Oct., respectively, for 'Kwik Krop'.

${ }^{\mathrm{y}} \mathrm{df}=$ degrees of freedom; $\mathrm{C}=$ chroma; $\mathrm{H}=$ hue angle; $\mathrm{LCH}$ sum $=\mathrm{L} *+\mathrm{C}+\mathrm{H}$.

Ns, $, * *, * * *$ Nonsignificant or significant at $P \leq 0.05,0.01$, or 0.001 , respectively.
LCH sum of 'Sparrow' kernels from immediately hulled fruits was 137 in Week 1 and dropped to 107 by Week 5 with the largest weekly change occurring from Week 3 to Week 4 (Fig. 2C). Using the color classification described by Brawner and Warmund (2008), kernels of 'Sparrow' fruits sampled at the recommended harvest date (Week 3) were in the medium brown color category, but they were in the dark category the next week. Thus, results of this study indicate that the recommended time of harvest may need to be modified if a specific kernel color is desired. Although the current study was limited to the evaluation of kernel color, earlier work (Brawner and Warmund, 2008) showed that percent kernel of 'Emma K' and 'Sparrow' increased linearly during a similar 5-week harvest period in 2005 and kernel color had varying responses over time. The reason for the different color responses in the two studies may be related to the use of different trees in a different section of the orchard. Nevertheless, these studies indicate that maximum percent kernel often occurs at Week 5, when kernel color may be dark brown. Thus, maximum percent kernel with a light-colored kernel may not be achieved at the same harvest date. Thus, percent kernel may be sacrificed to obtain light-colored kernels for some cultivars.

Although color and maximum percent kernel are major factors in harvesting black walnut, flavor is also important. Chase (1941) reported that black walnut kernels from fruits left unhulled for 3 weeks had a "strong" flavor, whereas those from fruits hulled immediately had a "mild" flavor. In a recent study conducted with a trained sensory panel, light- and medium-colored kernels (classified by spectrophotometer values) of 'Emma K' and 'Sparks 127' were characterized by buttery, caramelized, and sweet flavors, whereas dark-colored kernels had greater rancid, acrid, and bitter ratings (M.R. Warmund, unpublished data). These results indicate that late harvest dates may be avoided to decrease the likelihood of undesirable flavors associated with dark brown-colored kernels.

In conclusion, delayed harvesting and hulling resulted in darker brown-colored kernels for 'Emma K', 'Kwik Krop', and 'Sparrow'. Kernels from 'Sparrow' fruits harvested on 20 Sept. (Week 3) and immediately hulled exhibited a color change from medium brown to a dark brown when harvested a week later. Although visual changes in kernel color may be difficult to detect for a 

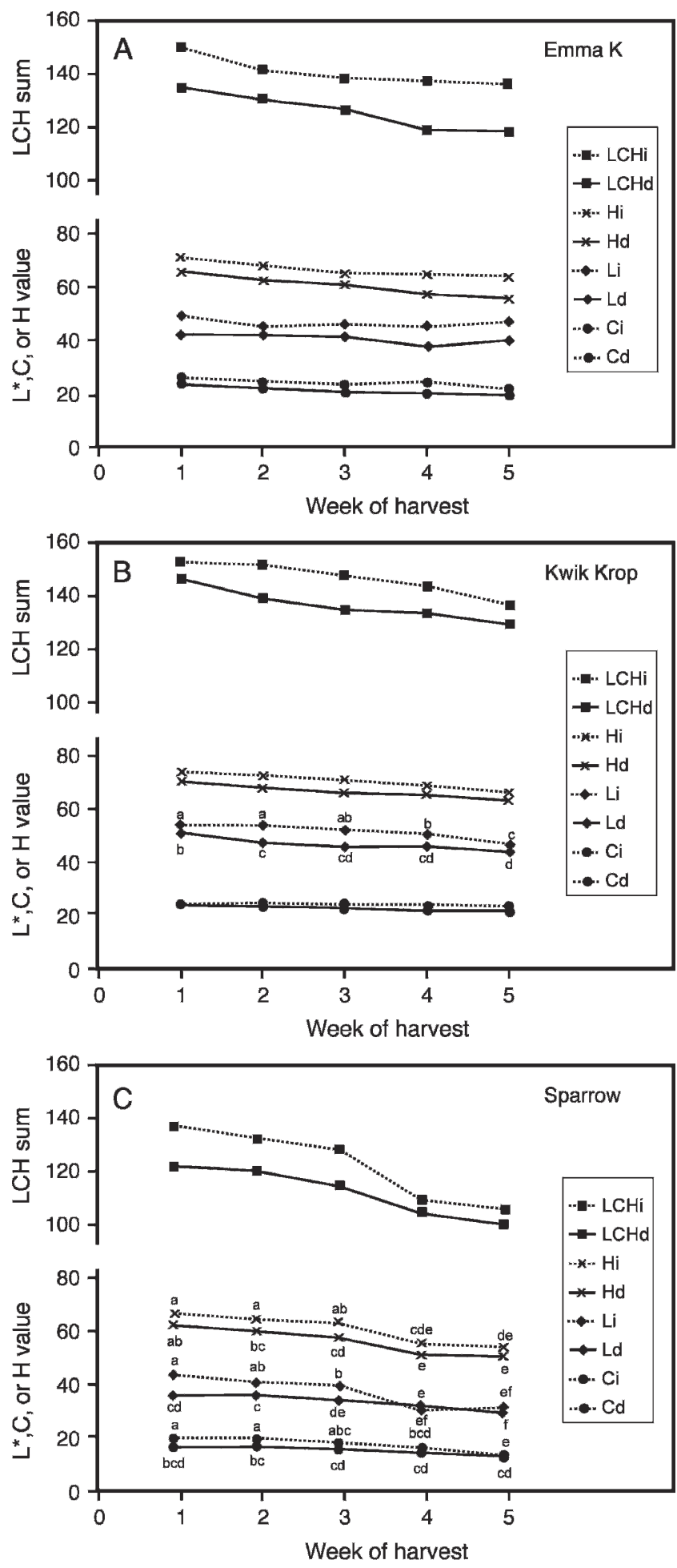

Fig. 2. The effect of delayed hulling and week of harvest on kernel color of (A) 'Emma K', (B) 'Kwik Krop', and $(\mathbf{C})$ 'Sparrow' black walnut. $\mathrm{Li}=\mathrm{L}^{*}$ value of kernels from fruits hulled immediately after harvest; $\mathrm{Ld}=\mathrm{L}^{*}$ value of kernels from fruits with delayed hulling ( 2 weeks after harvest); $\mathrm{C} i=$ chroma value of kernels from fruits hulled immediately after harvest; $\mathrm{Cd}=$ chroma value of kernels from fruits with delayed hulling; $\mathrm{Hi}=$ hue angle value of kernels from fruits hulled immediately after harvest; $\mathrm{Hd}=$ hue angle value of kernels from fruits with delayed hulling; $\mathrm{LCHi}=\mathrm{L}^{*}+$ chroma $(\mathrm{C})+$ hue $(\mathrm{H})$ angle values of kernels from fruits hulled immediately after harvest; LCHd $=\mathrm{L}^{*}+$ chroma $(\mathrm{C})+$ hue $(\mathrm{H})$ angle values of kernels from fruits with delayed hulling. A spectrophotometer was used to obtain color values. Week 3 is the "normal" date of harvest. Weekly means for each color variable and hulling treatment with different letters were significantly different by Fisher's protected least significant difference test $(P \leq 0.05)$. Data points without letters are not significantly different. cultivar such as Kwik Krop, quantitative changes in $\mathrm{L}^{*}, \mathrm{C}$, and $\mathrm{H}$ are readily detected with the spectrophotometer.

\section{Literature Cited}

Brawner, S.A. and M.R. Warmund. 2008. Husk softening and kernel characteristics of three black walnut cultivars at successive harvest dates. HortScience 43:691-695.

Chase, S.B. 1941. The effect of handling methods on the color and flavor of black walnut kernels. Northern Nut Growers Assn. Annu. Rep. 32:34-37.

Duke, J.A. 2001. Handbook of nuts, p. 190-193. CRC Press, Boca Raton, FL.

Funk, D.T. 1979. Black walnuts for nuts and timber, p. 51-73. In: Jaynes, R.A. (ed.). Nut tree culture in North America. Northern Nut Growers Assn., Inc., Hamden, CT.

Lane, B. 2000. Notes from over a quarter-century of building black walnut processing equipment. The nutshell. Northern Nut Growers Assoc. 54:1-12.

McGuire, R.G. 1992. Reporting of objective color measurements. HortScience 27:1254-1255.

Reid, W., M.V. Coggeshall, and K.L. Hunt. 2004. Cultivar evaluation and development for black walnut orchards. Proc. 6th Walnut Council Research Symposium. USDA Gen. Tech. Rpt. NC-243.

Stoke, H.F. 1941. Factors influencing the color and quality of black walnut kernels. Northern Nut Growers Assoc. Annu. Rep. 32:37-41.

Taylor, J.L. and R.L. Perry. 1986. Growing nuts. North Central Reg. Ext. Publ. 237. East Lansing, MI.

Voss, D.H. 1992. Relating colorimeter measurement of plant color to the Royal Horticultural Society colour chart. HortScience 27:12561260. 